\title{
Apolipoprotein E polymorphism and the risk of intracranial aneurysms in a Chinese population
}

\author{
Hao Liu, Ping Mao, Changhou Xie, Wanfu Xie, Maode Wang and Haitao Jiang*
}

\begin{abstract}
Background: The relationship between the apolipoprotein E (APOE) polymorphism and intracranial aneurysms has previously only been studied in Russia and Japan but not in Chinese populations. The purpose of this study was to investigate the association between APOE polymorphism and the risk of intracranial aneurysms in a Chinese population.
\end{abstract}

Methods: The study population consisted of 150 intracranial aneurysms patients and 150 matched control subjects. The APOE gene polymorphism was analyzed using polymerase chain reaction-restriction fragment length polymorphism (PCR-RFLP).

Results: Patients with intracranial aneurysms had a significantly higher frequency of APOE E2/E2 genotype [odds ratio $(\mathrm{OR})=9.51,95 \%$ confidence interval $(\mathrm{Cl})=1.19,76.04 ; P=0.03$ ] and $A P O E$ E2/E3 genotype $(\mathrm{OR}=1.87,95 \%$ $\mathrm{Cl}=1.03,3.40 ; P=0.04)$ than healthy controls. The $A P O E$ E4/E4 genotype frequencies $(\mathrm{OR}=0.09,95 \% \mathrm{Cl}=0.01$, $0.74 ; P=0.03$ in the intracranial aneurysms group were significantly lower than those in the controls group. When stratified by the site, shape, size and the Fisher Grade of intracranial aneurysms, no statistically significant result was observed.

Conclusion: Our study suggested that APOE polymorphism might be associated with intracranial aneurysms in Chinese population. Additional studies are needed to confirm this finding.

Keywords: Apolipoprotein E, Gene polymorphism, Intracranial aneurysms

\section{Background}

Intracranial aneurysm is a fairly common condition that is often asymptomatic until the time of rupture. A systematic review of studies involving more than 56,000 patients found that unruptured intracranial aneurysms occur in 3.6 to $6 \%$ of the general population [1]. Rupture of intracranial aneurysms accounts for more than $90 \%$ of subarachnoid hemorrhage cases [2]. Intracranial aneurysms may result from diseases acquired during life, or from genetic conditions. Lifestyle diseases including hypertension, smoking, excess alcohol consumption, and obesity are associated with the development of aneurysms [3-5]. Genome-wide association studies (GWAS) of

\footnotetext{
* Correspondence: haitjiang@hotmail.com

Department of Neurosurgery, The First Affiliated Hospital of Xi'an Jiao Tong University, West Yanta Road No.277, Xi'an 710061, China
}

intracranial aneurysm in European and Japanese casecontrol cohorts have identified several new risk loci [6-9].

Apolipoprotein E (apoE), a 299-amino acid, argininerich glycoprotein, is an integral surface component of chylomicrons, very-low-density lipoproteins, and some subclasses of high-density lipoproteins [10, 11]. The $A P O E$ gene is polymorphic, consisting of 3 common alleles (E2, E3, and E4) and 6 different genotypes (E2/E2, E2/E3, E2/E4, E3/E3, E3/E4 and E4/E4) [11]. APOE gene polymorphisms seem to have some impact among patients with cardiovascular disease [12].

The relationship between the APOE polymorphism and intracranial aneurysms has previously only been studied in Russia and Japan but not in Chinese populations [13, 14]. The purpose of this study was to investigate the association between $A P O E$ polymorphisms and the risk of intracranial aneurysms in a Chinese population. 


\section{Methods}

\section{Study population}

A hospital-based case-control study was conducted in 150 patients with intracranial aneurysms and 150 ageand gender-matched healthy controls during the years 2009 to 2014 in the Department of Neurosurgery, The First Affiliated Hospital of Xi'an Jiao Tong University, China. Peripheral blood specimens and demographic, medical, and family histories were obtained from sequentially ascertained, unrelated patients. Intracranial aneurysms in the cases were confirmed by magnetic resonance imaging (MRI) or computed tomography angiography (CTA) or cerebral angiography. Most intracranial aneurysms cases have no symptoms and may only be discovered during tests for another, usually unrelated, condition. The healthy control subjects were collected from the same geographic region and were attending a clinic for routine examination in the Department of Neurosurgery, The First Affiliated Hospital of Xi'an Jiao Tong University. The control subjects met the following criteria: (1) confirmation of the absence of intracranial aneurysms by digital subtraction angiography, magnetic resonance angiography, or 3-dimensional computed tomography angiography; (2) a similar age and sex distribution; (3) no medical history of any vascular disease, including intracranial aneurysms or subarachnoid hemorrhage; (4) no family history of intracranial aneurysms or subarachnoid hemorrhage in first-degree relatives; and (5) the same population as the cases. The Ethical Committee of the First Affiliated Hospital of Xi'an Jiao Tong University approved the study protocols, and all participants gave written informed consent according to the Declaration of Helsinki.

\section{DNA extraction and genotyping}

The commercially available Qiagen kit (QIAGEN Inc., Valencia, CA, USA) was used to extract DNA from peripheral blood leukocytes. Polymerase chain reaction restriction fragment length polymorphism (PCR-RFLP) assay was applied to assess the $A P O E$ gene polymorphisms. Based on the GenBank reference sequence, the PCR primers were as follows: sense, ACAGAATTCGCCCCGGCCTGGTACAC; antisense, TAAGCTTGGCACGGCTGTCCAAGGA. The amplified PCR products were then digested with $2 \mathrm{U}$ of Hha I (New England BioLabs, Missisauga, ON, Canada) at $37{ }^{\circ} \mathrm{C}$ for $3 \mathrm{~h}$. The resulting DNA fragments were electrophoresed on $3.5 \%$ agarose gel and visualized under UV light after ethidum staining.

\section{Statistical analysis}

The Statistical Analyses System (SAS) package (version 8.01; SAS Institute, Cary, NC) was used for statistical analysis. Differences between continuous variables were assessed by Student's $t$ test, while those between categorical variables were evaluated using Pearson $x^{2}$ test. The existence of differences in genotypic frequencies between groups was assessed by means of Pearson $x^{2}$ test and calculating the odds ratio (OR) with the $95 \%$ confidence intervals (CI). A P-value was considered significant at a level of $<0.05$. A chi-square test was used to confirm that the $A P O E$ genotype frequencies were in HardyWeinberg equilibrium.

\section{Results}

The characteristics of patients with intracranial aneurysms and controls were shown in Table 1. As to clinical characteristics, there was no statistical significant difference in gender, age or the prevalence of risk factors including hypertension, smoking and drinking between the patient with intracranial aneurysms and control groups, as shown in Table 1 . The site of aneurysm was as follows: anterior cerebral artery, 67 (44.7\%); internal carotid artery, 53 (35.3\%); and middle cerebral artery, 30 (20.0\%). The shape of aneurysm was as follows: saccular, 119 (79.3 \%); fusiform, 24 (16.0\%); dissecting, 7 (4.7 \%).

Table 1 Characteristics of patients with intracranial aneurysms and controls

\begin{tabular}{|c|c|c|c|}
\hline & Aneurysms & Controls & $P$ \\
\hline Total No. & 150 & 150 & \\
\hline Gender (Male/Female) & $67 / 83$ & $65 / 85$ & 0.82 \\
\hline Age (years) & $46.7 \pm 10.9$ & $47.2 \pm 11.2$ & 0.70 \\
\hline Hypertension (Yes/No) & $53 / 97$ & $49 / 101$ & 0.63 \\
\hline Smoking (Yes/No) & $37 / 113$ & $35 / 115$ & 0.79 \\
\hline Drinking (Yes/No) & $31 / 119$ & $30 / 120$ & 0.89 \\
\hline \multicolumn{4}{|l|}{ Site of aneurysm (\%) } \\
\hline ACA & $67(44.7)$ & / & \\
\hline ICA & $53(35.3)$ & / & \\
\hline MCA & $30(20.0)$ & / & \\
\hline \multicolumn{4}{|l|}{ Shape of aneurysm (\%) } \\
\hline Saccular & 119(79.3) & / & \\
\hline Fusiform & $24(16.0)$ & / & \\
\hline Dissecting & $7(4.7)$ & / & \\
\hline \multicolumn{4}{|l|}{ Size of aneurysm (\%) } \\
\hline Small (<15 mm) & 106(70.7) & / & \\
\hline Larger (15-25 mm) & $37(24.7)$ & / & \\
\hline Giant (>25 mm) & $7(4.6)$ & / & \\
\hline \multicolumn{4}{|l|}{ The Fisher Grade } \\
\hline Grade 1 & $14(9.4)$ & / & \\
\hline Grade 2 & $74(49.3)$ & / & \\
\hline Grade 3 & $44(29.3)$ & / & \\
\hline Grade 4 & 18(12.0) & / & \\
\hline
\end{tabular}

ACA, anterior cerebral artery; ICA, internal carotid artery; MCA, middle cerebral artery. Smoking was defined as non-smoker (smoked less than 100 cigarettes in lifetime) and smoker. Drinking was defined as non-drinker and drinker (consumed more than one cup, $200 \mathrm{~mL}$, per day) 
The size of aneurysm was as follows: small $(<15 \mathrm{~mm})$, 106 (70.7 \%); larger (15-25 mm), 37 (24.7\%); giant ( $>25 \mathrm{~mm}), 7$ (4.6\%). The Fisher Grade was as follows: Grade 1, 14 (9.4 \%); Grade 2, 74 (49.3\%); Grade 3, 44 (29.3\%); Grade 4, 18 (12.0 \%) (Table 1).

Patients with intracranial aneurysms had a significantly higher frequency of $A P O E \mathrm{E} 2 / \mathrm{E} 2$ genotype $(\mathrm{OR}=9.51$, $95 \% \mathrm{CI}=1.19,76.04 ; P=0.03)$ and $A P O E \mathrm{E} 2 / \mathrm{E} 3$ genotype $(\mathrm{OR}=1.87,95 \% \mathrm{CI}=1.03,3.40 ; P=0.04)$ than healthy controls (Table 2). The APOE E4/E4 genotype frequencies $(\mathrm{OR}=0.09,95 \% \mathrm{CI}=0.01,0.74 ; P=0.03)$ in the intracranial aneurysms group were significantly lower than those in the controls group (Table 2). When stratified by the site, shape, size and the Fisher Grade of intracranial aneurysms, no statistically significant result was observed (Table 3).

\section{Discussion}

Although lot of studies have been conducted to examine the association of genetic polymorphism and intracranial aneurysms, the relationship between the APOE polymorphism and intracranial aneurysms has previously only been studied in Russia and Japan but not in Chinese populations [13, 14]. Evidence from a case-control study suggested that the collagen type I alpha2 gene polymorphism was associated with intracranial aneurysms in a subset of the German population [15]. Authors of a case-control study suggested that the $I L-12 A$ and $I L-12 B$ independently and jointly was involved in the susceptibility to intracranial aneurysms in a Chinese population [16]. Evidence from a meta-analysis included six case-control studies, which included 1188 intracranial aneurysms cases and 4099 controls, suggested that $I L-6$ promoter polymorphisms (-174G/C and -572G/C) were associated with intracranial aneurysms [17]. Authors of a case-control study in a Chinese population suggested that the $m i R-34 b / c$ rs4938723CC and TP53 Arg72-Pro polymorphisms may be involved in the susceptibility to intracranial aneurysms [18]. Evidence from a case-control study indicated that the elastin gene polymorphism might be associated with the formation and the rupture of intracranial aneurysms [19]. Evidence from a genetic meta-analysis of 8 genes and 13 polymorphisms

Table 2 Genotype frequencies of APOE gene polymorphisms among intracranial aneurysms cases and controls

\begin{tabular}{llllc}
\hline Genotype & Aneurysms & Controls & OR $(95 \% \mathrm{Cl})$ & $P$ value \\
\hline E2/E2 & $9(6.0)$ & $1(0.6)$ & $9.51(1.19,76.04)$ & 0.03 \\
E2/E3 & $35(23.3)$ & $21(14.0)$ & $1.87(1.03,3.40)$ & 0.04 \\
E2/E4 & $4(2.7)$ & $7(4.7)$ & $0.56(0.16,1.95)$ & 0.36 \\
E3/E3 & $76(50.7)$ & $80(53.3)$ & $0.90(0.57,1.41)$ & 0.64 \\
E3/E4 & $25(16.7)$ & $31(20.7)$ & $0.77(0.43,1.38)$ & 0.38 \\
E4/E4 & $1(0.6)$ & $10(6.7)$ & $0.09(0.01,0.74)$ & 0.03 \\
\hline
\end{tabular}

in approximately 20,000 individuals showed that there was a likely genetic basis to sporadic intracranial aneurysms. However, the evidence base was small when compared against other complex disorders [20]. Authors of a casecontrol study suggested that the NFKB1 -94ins/del ATTG polymorphism might contribute to the risk of intracranial aneurysms [21]. Polymorphisms within the kallikrein gene cluster are associated with intracranial aneurysms suggesting that the kallikreins are important candidate genes for intracranial aneurysms [22]. Evidence from a case-control study suggested that the angiotensin-converting enzyme DD genotype might be a protective factor for intracranial aneurysms in a Chinese population [23]. Evidence from a meta-analysis of case-control studies also suggested that there was a close relationship between angiotensinconverting enzyme I/D polymorphism and intracranial aneurysms risk [24]. The study by Pannu et al. and Peters et al. supported a role for $M M P-9$ in the pathogenesis of intracranial aneurysms [25, 26]. Genome-wide association study for intracranial aneurysm in the Japanese population identified three candidate susceptible loci and a functional genetic variant at EDNRA [8].

The $A P O E$ gene polymorphisms were also associated with many other diseases. Authors of a case-control study showed that the $A P O E$ epsilon polymorphism has the expected impact on the plasma lipid profile and the rs4420638 G allele may counterbalance the deleterious effect of the E4 allele on low-density lipoproteins (LDL)cholesterol levels in an Algerian population [11]. Evidence from a meta-analysis of 29 studies suggested that $A P O E$ gene polymorphisms was associated with the risk of vascular dementia [27]. Evidence from a meta-analysis of 28 case-control studies provided evidence for an association between the APOE E4 allele and frontotemporal lobar degeneration [28]. Authors of a case-control study found that $A P O E$ gene polymorphism was associated with maximal oxygen uptake levels after exercise training in Chinese young adult [29]. Evidence from a metaanalysis of experimental and human studies suggested an association between $A P O E$ gene expression and its gene polymorphism with nephrotic syndrome susceptibility [30]. Evidence from a meta-analysis of 45 studies found that $A P O E$ gene polymorphisms were associated with essential hypertension [31]. Authors of a hospitalbased case-control study suggested that APOE E3/E4 genotype was associated with a higher lower extremity deep venous thrombosis risk [32]. Evidence from a meta-analysis of seven studies suggested that the $A P O E$ polymorphisms were associated with the risk of psoriasis, especially E2 and E3 alleles [33]. A meta-analysis of seven studies suggested an association between $A P O E$ E4 mutation and increased risk of recurrent pregnancy loss [34]. Evidence from a meta-analysis of 6977 subjects provides evidence that $A P O E$ E2 mutation is associated 
Table 3 Stratification analysis of APOE genotype frequency in intracranial aneurysms

\begin{tabular}{|c|c|c|c|c|c|c|c|c|c|c|c|c|c|}
\hline \multirow[t]{2}{*}{ Variable } & \multirow[t]{2}{*}{ Cases } & \multicolumn{2}{|l|}{ E2/E2 } & \multicolumn{2}{|l|}{ E2/E3 } & \multicolumn{2}{|l|}{ E2/E4 } & \multicolumn{2}{|l|}{ E3/E3 } & \multicolumn{2}{|l|}{ E3/E4 } & \multicolumn{2}{|l|}{ E4/E4 } \\
\hline & & n (\%) & $P$ & n (\%) & $P$ & n (\%) & $P$ & $n(\%)$ & $P$ & n (\%) & $P$ & n (\%) & $P$ \\
\hline Site of aneurysm (\%) & 150 & $9(6.0)$ & & $35(23.3)$ & & $4(2.7)$ & & $76(50.7)$ & & $25(16.7)$ & & $1(0.6)$ & \\
\hline ACA & 67 & $4(6.0)$ & 0.99 & $16(23.9)$ & 0.95 & $2(3.0)$ & 0.90 & $33(49.2)$ & 0.91 & $11(16.4)$ & 0.97 & $1(1.5)$ & 0.57 \\
\hline ICA & 53 & $3(5.7)$ & 0.93 & $12(22.6)$ & 0.94 & 1(1.9) & 0.76 & $28(52.8)$ & 0.88 & $9(17.0)$ & 0.97 & $0(0)$ & 0.97 \\
\hline MCA & 30 & $2(6.7)$ & 0.90 & $7(23.3)$ & 1.00 & $1(3.3)$ & 0.84 & $15(50.0)$ & 0.97 & $5(16.7)$ & 1.00 & $0(0)$ & 0.76 \\
\hline Shape of aneurysm (\%) & 150 & $9(6.0)$ & & $35(23.3)$ & & $4(2.7)$ & & $76(50.7)$ & & $25(16.7)$ & & $1(0.6)$ & \\
\hline Saccular & 119 & $5(4.2)$ & 0.53 & $27(22.7)$ & 0.92 & $2(1.7)$ & 0.60 & $64(53.8)$ & 0.78 & $20(16.8)$ & 0.98 & $1(0.8)$ & 0.87 \\
\hline Fusiform & 24 & $3(12.5)$ & 0.30 & $6(25.0)$ & 0.89 & $1(4.1)$ & 0.70 & $10(41.7)$ & 0.63 & $4(16.7)$ & 1.00 & $0(0)$ & 0.66 \\
\hline Dissecting & 7 & $1(14.3)$ & 0.44 & $2(28.6)$ & 0.81 & $1(14.3)$ & 0.16 & $2(28.6)$ & 0.48 & $1(14.3)$ & 0.89 & $0(0)$ & 0.26 \\
\hline Size of aneurysm (\%) & 150 & $9(6.0)$ & & $35(23.3)$ & & $4(2.7)$ & & $76(50.7)$ & & $25(16.7)$ & & $1(0.6)$ & \\
\hline Small (<15 mm) & 106 & $4(3.8)$ & 0.45 & $26(24.5)$ & 0.86 & $3(2.8)$ & 0.94 & 54(50.9) & 0.98 & 18(17.0) & 0.96 & $1(1.0)$ & 0.81 \\
\hline Larger (15-25 mm) & 37 & $4(10.8)$ & 0.35 & 7(18.9) & 0.64 & $1(2.7)$ & 0.99 & 19(51.4) & 0.97 & $6(16.2)$ & 0.96 & $0(0)$ & 0.86 \\
\hline Giant (>25 mm) & 7 & $1(14.3)$ & 0.44 & $2(28.6)$ & 0.81 & $0(0)$ & 0.60 & $3(42.8)$ & 0.81 & $1(14.3)$ & 0.89 & $0(0)$ & 0.26 \\
\hline The Fisher Grade & 150 & $9(6.0)$ & & $35(23.3)$ & & $4(2.7)$ & & $76(50.7)$ & & $25(16.7)$ & & $1(0.6)$ & \\
\hline Grade 1 & 14 & $1(7.1)$ & 0.87 & $3(21.4)$ & 0.90 & $0(0)$ & 0.93 & $8(57.2)$ & 0.80 & $2(14.3)$ & 0.53 & $0(0)$ & 0.45 \\
\hline Grade 2 & 74 & $5(6.8)$ & 0.84 & $18(24.3)$ & 0.90 & $2(2.7)$ & 0.99 & $35(47.3)$ & 0.78 & 13(17.6) & 0.89 & $1(1.3)$ & 0.62 \\
\hline Grade 3 & 44 & $2(4.5)$ & 0.73 & $10(22.7)$ & 0.95 & $2(4.5)$ & 0.55 & $23(52.3)$ & 0.92 & 7(15.9) & 0.92 & $0(0)$ & 0.94 \\
\hline Grade 4 & 18 & $1(5.5)$ & 0.94 & $4(22.2)$ & 0.93 & $0(0)$ & 0.95 & $10(55.6)$ & 0.83 & $3(16.7)$ & 1.00 & $0(0)$ & 0.55 \\
\hline
\end{tabular}

with multiple sclerosis risk [35]. Evidence from a metaanalysis included 29 studies suggested that $A P O E$ E4 allele was associated with an increased risk of developing cerebral infarction in Chinese population [36].

The exact molecular mechanism of the association between APOE polymorphism and the risk of intracranial aneurysms remains relatively unclear. APOE plays a critical role in redistributing lipids among central nervous system cells for normal lipid homeostasis [37, 38], repairing injured neurons [39], maintaining synaptodendritic connections [40], neurite outgrowth [41], synaptic plasticity [42], mitochondrial resistance to oxidative stress [43], and glucose use by neurons and glial cells $[44,45]$. A case-control study in Russia found that intracranial aneurysms with hypertension were associated with the e2 allele and the e2/e3 APOE genotype [13]. This was consistent with our study.

There are some limitations to the present study that should be mentioned. First of all, although this study suggested that $A P O E$ polymorphism was associated with intracranial aneurysms, more biological background data are needed to explain our results. The current finding might involve gene-to-environment interactions, which were not explored in the present study. Second, the sample size of this study is relatively small, which may not have enough statistical power to explore the real association. Third, this is a hospital based case control study and selection bias cannot be avoided and therefore the subjects may not be representative of the general population within China. Finally, these results should be interpreted with caution because the population was only from China, which reduces the possibility of confounding from ethnicity, however does not permit extrapolation of the results to other ethnic groups.

\section{Conclusions}

In conclusion, our study suggested that $A P O E$ polymorphism might be associated with intracranial aneurysms in Chinese population. Additional studies are needed to confirm this finding.

\section{Competing interests}

The authors declare that they have no competing interests.

\section{Authors' contributions}

$\mathrm{HL}$ and $\mathrm{HJ}$ carried out the molecular genetic studies and drafted the manuscript. PM and CX carried out the genotyping. WX and MW participated in the design of the study and performed the statistical analysis. HL, PM, CX, WX, MW and HJ conceived of the study, and participated in its design and coordination and helped to draft the manuscript. All authors read and approved the final manuscript.

\section{Acknowledgements}

Thanks are expressed to all coinvestigators, local project coordinators, research assistants, laboratory technicians, and secretaries/administrative assistants.

Received: 24 May 2015 Accepted: 19 January 2016

Published online: 29 January 2016

\section{References}

1. Rinkel GJ, Djibuti M, Algra A, van Gijn J. Prevalence and risk of rupture of intracranial aneurysms: a systematic review. Stroke. 1998;29(1):251-6.

2. Inagawa T. Trends in incidence and case fatality rates of aneurysmal subarachnoid hemorrhage in Izumo City, Japan, between 1980-1989 and 1990-1998. Stroke. 2001;32(7):1499-507. 
3. Broderick JP, Viscoli CM, Brott T, Kernan WN, Brass LM, Feldmann E, et al. Major risk factors for aneurysmal subarachnoid hemorrhage in the young are modifiable. Stroke. 2003;34(6):1375-81. doi:10.1161/01.STR.0000074572. 91827.F4.

4. Ruigrok YM, Rinkel GJ, Wijmenga C. Genetics of intracranial aneurysms. Lancet Neurol. 2005:4(3):179-89. doi:10.1016/S1474-4422(05)01015-X.

5. Nahed BV, Bydon M, Ozturk AK, Bilguvar K, Bayrakli F, Gunel M. Genetics of intracranial aneurysms. Neurosurgery. 2007;60(2):213-25. doi:10.1227/01.NEU. 0000249270.18698.BB. discussion 25-6.

6. Foroud T, Lai D, Koller D, Van't Hof F, Kurki MI, Anderson CS, et al. Genomewide association study of intracranial aneurysm identifies a new association on chromosome 7. Stroke. 2014;45(11):3194-9. doi:10.1161/STROKEAHA.114. 006096

7. Bakir-Gungor B, Sezerman OU. The identification of pathway markers in intracranial aneurysm using genome-wide association data from two different populations. PLoS One. 2013;8(3):e57022. doi:10.1371/journal.pone.0057022

8. Low SK, Takahashi A, Cha PC, Zembutsu H, Kamatani N, Kubo M, et al. Genome-wide association study for intracranial aneurysm in the Japanese population identifies three candidate susceptible loci and a functional genetic variant at EDNRA. Hum Mol Genet. 2012;21(9):2102-10. doi:10.1093/hmg/dds020.

9. Yasuno K, Bilguvar K, Bijlenga P, Low SK, Krischek B, Auburger G, et al. Genome-wide association study of intracranial aneurysm identifies three new risk loci. Nat Genet. 2010;42(5):420-5. doi:10.1038/ng.563.

10. Smalinskiene A, Petkeviciene J, Luksiene D, Jureniene K, Klumbiene J, Lesauskaite V. Association between APOE, SCARB1, PPARalpha polymorphisms and serum lipids in a population of Lithuanian adults. Lipids Health Dis. 2013;12:120. doi:10.1186/1476-511X-12-120.

11. Boulenouar H, Mediene Benchekor S, Meroufel DN, Lardjam Hetraf SA, Ouhaibi Djellouli H, Hermant X, et al. Impact of APOE gene polymorphisms on the lipid profile in an Algerian population. Lipids Health Dis. 2013;12:155. doi:10.1186/1476-511X-12-155.

12. Eichner JE, Dunn ST, Perveen G, Thompson DM, Stewart KE, Stroehla BC. Apolipoprotein E polymorphism and cardiovascular disease: a HuGE review. Am J Epidemiol. 2002;155(6):487-95.

13. Lebedeva ER, Sakovich VP, Khusainova RI, Kutuev IA, Valiev RR, Khusnutdinova NN, et al. The role of angiotensin-converting enzyme and apolipoprotein E in the development of intracranial aneurysms. Zh Nevrol Psikhiatr Im S S Korsakova. 2007;107(10):52-7.

14. Mineharu Y, Inoue K, Inoue S, Yamada S, Nozaki K, Takenaka K, et al. Association analysis of common variants of ELN, NOS2A, APOE and ACE2 to intracranial aneurysm. Stroke. 2006;37(5):1189-94. doi:10.1161/01.STR. $0000217408.91389 .4 d$.

15. Glasker S, Schatlo B, Klingler JH, Braun V, Spangenberg P, Kim IS, et al. Associations of collagen type I alpha2 polymorphisms with the presence of intracranial aneurysms in patients from Germany. J Stroke Cerebrovasc Dis. 2014:23(2):356-60. doi:10.1016/i.jstrokecerebrovasdis.2013.04.038.

16. Li LJ, Pan XM, Sima X, Li ZH, Zhang LS, Sun H, et al. Interactions of interleukin-12A and interleukin-12B polymorphisms on the risk of intracranial aneurysm. Mol Biol Rep. 2012;39(12):11217-23. doi:10.1007/ s11033-012-2031-z.

17. Zheng S, Su A, Sun H, You C. The association between interleukin- 6 gene polymorphisms and intracranial aneurysms: a meta-analysis. Hum Immunol. 2013;74(12):1679-83. doi:10.1016/j.humimm.2013.08.274.

18. Li L, Sima X, Bai P, Zhang L, Sun H, Liang W, et al. Interactions of miR-34b/c and TP53 polymorphisms on the risk of intracranial aneurysm. Clin Dev Immunol. 2012;2012:567586. doi:10.1155/2012/567586.

19. Yang S, Wang T, You C, Liu W, Zhao K, Sun H, et al. Association of polymorphisms in the elastin gene with sporadic ruptured intracranial aneurysms and unruptured intracranial aneurysms in Chinese patients. Int J Neurosci. 2013;123(7):454-8. doi:10.3109/00207454.2013.763803.

20. McColgan $P$, Thant $K Z$, Sharma $P$. The genetics of sporadic ruptured and unruptured intracranial aneurysms: a genetic meta-analysis of 8 genes and 13 polymorphisms in approximately 20,000 individuals. J Neurosurg 2010;112(4):714-21. doi:10.3171/2009.8.JNS092.

21. Sima X, Xu J, Li J, You C. Association between NFKB1 -94 insertion/deletion ATTG polymorphism and risk of intracranial aneurysm. Genet Test Mol Biomarkers. 2013:17(8):620-4. doi:10.1089/gtmb.2013.0110.

22. Weinsheimer S, Goddard KA, Parrado AR, Lu Q, Sinha M, Lebedeva ER, et al. Association of kallikrein gene polymorphisms with intracranial aneurysms. Stroke. 2007;38(10):2670-6. doi:10.1161/STROKEAHA.107.486225.
23. Liu Y, Li P, Hu X, Hu Y, Sun HG, Ma WC, et al. Angiotensin-converting enzyme insertion/deletion gene polymorphism and risk of intracranial aneurysm in a Chinese population. J Int Med Res. 2013;41(4):1079-87. doi:10.1177/0300060513487625.

24. Chen Z, Ma J, Cen Y, Liu Y, You C. The angiotensin converting enzyme insertion/deletion polymorphism and intracranial aneurysm: a meta-analysis of case-control studies. Neurol India. 2013;61(3):293-9. doi:10.4103/00283886.115071.

25. Pannu H, Kim DH, Guo D, King TM, Van Ginhoven G, Chin T, et al. The role of MMP-2 and MMP-9 polymorphisms in sporadic intracranial aneurysms.

J Neurosurg. 2006;105(3):418-23. doi:10.3171/jns.2006.105.3.418.

26. Peters DG, Kassam A, St Jean PL, Yonas H, Ferrell RE. Functional polymorphism in the matrix metalloproteinase-9 promoter as a potential risk factor for intracranial aneurysm. Stroke. 1999;30(12):2612-6.

27. Yin YW, Li JC, Wang JZ, Li BH, Pi Y, Yang QW, et al. Association between apolipoprotein $\mathrm{E}$ gene polymorphism and the risk of vascular dementia: a meta-analysis. Neurosci Lett. 2012;514(1):6-11. doi:10.1016/j.neulet.2012.02.031.

28. Rubino E, Vacca A, Govone F, De Martino P, Pinessi L, Rainero I. Apolipoprotein E polymorphisms in frontotemporal lobar degeneration: a meta-analysis. Alzheimers Demen. 2013;9(6):706-13. doi:10.1016/j.jalz. 2012.10.013.

29. Yu B, Chen W, Wang R, Qi Q, Li K, Zhang W, et al. Association of apolipoprotein E polymorphism with maximal oxygen uptake after exercise training: a study of Chinese young adult. Lipids Health Dis. 2014;13(1):40. doi:10.1186/1476-511X-13-40.

30. Zhou TB, Qin YH, Xu HL. Association of apoE gene expression and its gene polymorphism with nephrotic syndrome susceptibility: a meta-analysis of experimental and human studies. Mol Biol Rep. 2012;39(10):9347-54. doi:10.1007/s11033-012-1751-4

31. Stoumpos S, Hamodrakas SJ, Anthopoulos PG, Bagos PG. The association between apolipoprotein $\mathrm{E}$ gene polymorphisms and essential hypertension: a meta-analysis of 45 studies including 13,940 cases and 16,364 controls. J Hum Hypertens. 2013;27(4):245-55. doi:10.1038/jhh.2012.37.

32. Zhu S, Wang Z, Wu X, Shu Y, Lu D. Apolipoprotein E polymorphism is associated with lower extremity deep venous thrombosis: color-flow Doppler ultrasound evaluation. Lipids Health Dis. 2014;13:21. doi:10.1186/ 1476-511X-13-21.

33. Han Y, Liu T, Lu L. Apolipoprotein E gene polymorphism in psoriasis: a meta-analysis. Arch Med Res. 2013;44(1):46-53. doi:10.1016/j.arcmed. 2012.10.009.

34. Meng HX, Qi MG, Yi YY, Liu YP. Association between apolipoprotein E gene polymorphism and the risk of recurrent pregnancy loss: a meta-analysis. J Assist Reprod Genet. 2013;30(12):1547-52. doi:10.1007/s10815-013-0118-7.

35. Yin YW, Zhang YD, Wang JZ, Li BH, Yang QW, Fang CQ, et al. Association between apolipoprotein $\mathrm{E}$ gene polymorphism and the risk of multiple sclerosis: a meta-analysis of 6977 subjects. Gene. 2012;511(1):12-7. doi:10.1016/j.gene.2012.09.010.

36. Wang QY, Wang WJ, Wu L, Liu L, Han LZ. Meta-analysis of APOE epsilon2/ epsilon3/epsilon4 polymorphism and cerebral infarction. J Neural Transm. 2013;120(10):1479-89. doi:10.1007/s00702-013-1019-8.

37. Gong JS, Kobayashi M, Hayashi H, Zou K, Sawamura N, Fujita SC, et al. Apolipoprotein $E$ (ApoE) isoform-dependent lipid release from astrocytes prepared from human ApoE3 and ApoE4 knock-in mice. J Biol Chem. 2002;277(33):29919-26. doi:10.1074/jbc.M203934200.

38. Fagan AM, Holtzman DM, Munson G, Mathur T, Schneider D, Chang LK, et al. Unique lipoproteins secreted by primary astrocytes from wild type, apoE (-/-), and human apoE transgenic mice. J Biol Chem. 1999; 274(42):30001-7.

39. Buttini M, Orth M, Bellosta S, Akeefe H, Pitas RE, Wyss-Coray T, et al. Expression of human apolipoprotein E3 or E4 in the brains of Apoe-/mice: isoform-specific effects on neurodegeneration. J Neurosci. 1999; 19(12):4867-80.

40. Nathan BP, Bellosta S, Sanan DA, Weisgraber KH, Mahley RW, Pitas RE. Differential effects of apolipoproteins E3 and E4 on neuronal growth in vitro. Science. 1994;264(5160):850-2

41. Bellosta S, Nathan BP, Orth M, Dong LM, Mahley RW, Pitas RE. Stable expression and secretion of apolipoproteins E3 and E4 in mouse neuroblastoma cells produces differential effects on neurite outgrowth. J Biol Chem. 1995;270(45):27063-71. 
42. Trommer BL, Shah C, Yun SH, Gamkrelidze G, Pasternak ES, Ye GL, et al. ApoE isoform affects LTP in human targeted replacement mice. Neuroreport. 2004;15(17):2655-8.

43. Gibson GE, Haroutunian V, Zhang H, Park LC, Shi Q, Lesser M, et al. Mitochondrial damage in Alzheimer's disease varies with apolipoprotein E genotype. Ann Neurol. 2000;48(3):297-303.

44. Reiman EM, Chen K, Alexander GE, Caselli RJ, Bandy D, Osborne D, et al. Functional brain abnormalities in young adults at genetic risk for late-onset Alzheimer's dementia. Proc Natl Acad Sci U S A. 2004;101(1):284-9. doi:10.1073/pnas.2635903100.

45. Biffi A, Sonni A, Anderson CD, Kissela B, Jagiella JM, Schmidt H, et al. Variants at APOE influence risk of deep and lobar intracerebral hemorrhage. Ann Neurol. 2010;68(6):934-43. doi:10.1002/ana.22134.

Submit your next manuscript to BioMed Central and we will help you at every step:

- We accept pre-submission inquiries

- Our selector tool helps you to find the most relevant journal

- We provide round the clock customer support

- Convenient online submission

- Thorough peer review

- Inclusion in PubMed and all major indexing services

- Maximum visibility for your research

Submit your manuscript at www.biomedcentral.com/submit
Biomed Central 